\title{
Do Ethical Leaders Get Ahead? Exploring Ethical Leadership and Promotability
}

\author{
Robert S. Rubin, Erich C. Dierdorff, and Michael E. Brown
}

\begin{abstract}
Despite sustained attention to ethical leadership in organizations, scholarship remains largely descriptive. This study employs an empirical approach to examine the consequences of ethical leadership on leader promotability. From a sample of ninety-six managers from two independent organizations, we found that ethical leaders were increasingly likely to be rated by their superior as exhibiting potential to reach senior leadership positions. However, leaders who displayed increased ethical leadership were no more likely to be viewed as promotable in the near-term compared to those who displayed less ethical leadership. Our findings also show ethical culture and pressure to achieve results are important contextual factors that moderate the relationships between ethical leadership and leader promotability to senior leadership roles.
\end{abstract}

$\mathrm{D}$

ESPITE DECADES OF RESEARCH, discussions of ethical leadership in organizations are largely anecdotal and remain highly normative (Brown \& Treviño, 2006). This is not to say that the study of ethical leadership has been entirely ignored or unproductive. To the contrary, efforts have uncovered aspects of ethical leadership contributing to rich, descriptive information particularly regarding senior executives (Treviño, Brown, \& Hartman, 2003). Yet, as Brown, Treviño, and Harrison recently remarked, "little has been done to systematically develop an ethical leadership construct necessary for testing theory about its origins and outcomes" (Brown, Treviño, \& Harrison, 2005: 118). Recently, however, researchers have undertaken important first steps in defining and empirically assessing the nature of the ethical leadership construct. Using a social-scientific perspective, this burgeoning line of research (Brown et al., 2005; Mayer, Kuenzi, Greenbaum, Bardes, \& Salvador, 2009; Resick, Hanges, Dickson, \& Mitchelson, 2006) has sought to develop a descriptive model of ethical leadership that can be examined alongside other known leadership models; thereby, appropriately placing the construct within the nomological network of leadership constructs. The purpose of the present study is to continue this important line of inquiry by establishing primary relationships between ethical leadership and important outcomes. Such examinations have received particular mention in recent calls for systematic research on ethical leadership (Brown \& Treviño, 2006).

Specifically, we sought to directly extend this approach to ethical leadership in at least two ways. First, we examine the relationship between ethical leader behavior and important leader-level outcomes, namely, leader promotability. A close examination of the extant ethical leadership literature reveals that studies have exclusively focused on the effects of leadership on employees, to the large neglect of the effects on leaders themselves. Such neglect is not necessarily surprising considering the 
absence of leader-level outcomes in the broader leadership literature. In addition, despite decades of research regarding factors that contribute to managerial career mobility or success (e.g., Ng, Eby, Sorensen, \& Feldman, 2005), studies have yet to consider whether ethical behavior is antecedent to promotion or promotability. Second, we examine the moderating effects of two contextual factors (ethical culture and pressure to achieve results) on leader promotability. Investigating the context in which ethical leadership is practiced is crucial to understanding the consequences of such leadership behavior (Brown \& Treviño, 2006) and extends calls to incorporate elements of context into organizational and managerial research (Dierdorff, Rubin, \& Morgeson, 2009; Johns, 2006). To date, however, there has been little empirical research investigating the interaction of ethical leader behavior and important contextual factors such as ethical culture on important outcomes.

\section{BACKGROUND}

Fundamental to the study of leadership in organizations is the belief that leaders are a necessary component of organizational change, efficiency, and effectiveness. With the exception of a few theoretical perspectives describing specific situations in which leadership may not be necessary (Kerr \& Jermier, 1978), all leadership research rests on this basic tenet. A wealth of literature supports the notion that certain forms of positive leadership (e.g., transformational leadership, leader-member exchange, charismatic leadership, contingent reward behavior, and so forth) are associated with a wide array of individual and organizational outcomes. For example, previous research has shown that positive leadership in the form of transformational leadership is empirically linked to increases in employee satisfaction, motivation, commitment, and effort (Judge \& Piccolo, 2004; Lowe, Kroeck, \& Sivasurbramaniam, 1996). In contrast, substantial research indicates that negative forms of leadership (e.g., petty tyranny, supervisor aggression, abusive supervision) routinely result in deleterious individual and organizational outcomes. For example, under abusive supervision employees have been found to have decreased performance, citizenship, satisfaction, and perceived organizational justice. Further, such negative forms of leadership have been associated with increases in counterproductive and deviance behavior (cf. Tepper, 2007). In all, it is clear that when leaders engage in positive forms of leader behavior, benefits to individuals and organizations are ubiquitous.

Yet, largely absent from this empirical literature is attention paid to the ethical dimensions of positive leadership. Responding to this void, Brown and colleagues (2005) proffered the construct of ethical leadership, defining it as "the demonstration of normatively appropriate conduct through personal actions and interpersonal relationships, and the promotion of such conduct to followers through two-way communication, reinforcement and decision-making" (Brown et al., 2005: 120). As Brown et al. (2005) note, this definition places ethical leadership at the nexus of positive forms of leadership. In addition, such a perspective focuses squarely on leader behavior and disentangles personal qualities, attitudes, or other individual differences from actual behavior. 
Although research emanating from this perspective remains in a nascent stage, the evidence suggests that ethical leader behavior can have important positive effects on both individual and organizational effectiveness. For example, ethical leader behavior has been positively associated with employee pay fairness (Detert, Treviño, Burris, \& Andiappan, 2007), willingness to report ethical problems, providing extra effort, increased trust in the leader, and perceptions of effectiveness and satisfaction with one's leader (Brown et al., 2005). Similarly, ethical leadership has been positively linked with group-level citizenship behavior and negatively associated with grouplevel deviance (Mayer et al., 2009). In addition, there is evidence that ethical leader behavior is distinct from other forms of effective leadership (e.g., transformational leadership), negatively related to ineffective forms of leadership (e.g., abusive supervision), and generalizes across cultures (Resick et al., 2006).

Taken together, burgeoning theoretical and empirical work are lending significant credence to the systematic empirical study of ethical leadership as a critical element of positive and effective leadership. Yet the preponderance of evidence to date has focused on the impact of ethical leadership on employees and organizations. Thus, little is known about whether ethical leadership is associated with particular consequences for the leader him/herself. This omission is rather unfortunate as leaders occupy positions that provide them the potential to influence numerous people; often having far-reaching affects not only for his/her employees but the leader him/herself (Bass, 1990). Further, consequences of leaders' behavior such as social recognition, promotion, pay raises, and performance ratings serve as potent reinforcers that shape the manner in which leaders will act in future situations. Indeed, research has long suggested that ethical behavior is influenced by organizational rewards and punishments (Ashkanasy, Windsor, \& Treviño, 2006; Hegarty \& Sims, 1978; Tenbrunsel, 1998; Treviño, 1986; Treviño \& Youngblood, 1990). In this sense, understanding what outcomes leaders stand to gain for themselves by engaging in ethical leadership is critically important to researchers and practitioners hoping to increase the prevalence of ethical leadership.

\section{ETHICAL LEADERSHIP AND PROMOTABILITY}

One important leader performance outcome that has been linked to individual and organizational success is that of career mobility (Combs, Liu, Hall, \& Ketchen, 2006; Ng et al., 2005; Van Velsor \& Leslie, 1995) and promotability (DePater, Van Vianen, Bechtoldt, \& Klehe, 2009). Promotability has been defined as "the favorability of an employee's advancement prospects" (Greenhaus, Parasuraman, \& Wormley, 1990: 69) and includes judgments of an employee's capacity to perform at more senior levels (DePater et al., 2009). Although many factors are involved in leader promotability within organizations, few managers are promoted without the support and recommendation of their own direct supervisors. For instance, in a recent meta-analysis of predictors of career success, $\mathrm{Ng}$ et al. (2005) found that among other things, individuals who receive significant sponsorship were more likely to be satisfied with their careers, receive higher salaries, and experience more promotions than those without sponsors. Within the leadership literature, longitudinal research 
has suggested that engaging in positive forms of leader behavior is associated with increased promotions into senior-level positions over a career (Howard \& Bray, 1988; Lombardo, Ruderman, \& McCauley, 1987). Further, substantial work shows that leaders who engage in effective leadership styles, such as transformational leadership, are rewarded with increased job performance ratings from their direct superiors (Judge \& Piccolo, 2004). Similar research has shown that leaders who display effective and positive forms of leadership are increasingly seen as good organizational citizens (Podsakoff, MacKenzie, Paine, \& Bachrach, 2000) and thus more likely to contribute to the organization by going beyond expectations.

These findings above collectively suggest that leaders who employ positive leadership are more likely to garner support from superiors and more quickly progress within the organization. Such a perspective is further supported by signaling theory (Spence, 1973) which suggests that in making promotability evaluations, supervisors will rely on signals indicative of leaders' probability of success in future roles. That is, promotability judgments represent supervisory perceptions of leaders' expected performance at some time in the future for organizational roles yet assumed. Logically supervisors must base promotability evaluations on imperfect information about the potential to perform at higher levels. In such a situation where information remains imperfect, signaling theory suggests that supervisors' must rely on leaders' "observable characteristics and qualities . . . that are discretionary and that reflect their capacities and talents" (DePater et al., 2009: 302). Thus, supervisory evaluations of promotability rely heavily upon sets of signals that represent leaders' capabilities or suitability for promotion (Spence, 1973).

As a positive form of leadership, we therefore purport that ethical leadership provides strong positive signals and is positively associated with promotability or "getting ahead" for a number of reasons. First, leaders who display ethical leader behavior are more likely to be seen as trustworthy and fair (Brown \& Treviño, 2006). When leaders engage in behavior that is viewed as trustworthy, superiors are likely to interpret such behavior as professional and view the leader as dependable (McAllister, 1995). Second, research suggests that honesty and integrity, both critical dimensions of ethical leadership, are routinely related to perceived leader effectiveness (Hogan, Curphy, \& Hogan, 1994). Similarly, ethical leader behavior is predicated on leader fairness, which research has shown to be positively related to perceived leader effectiveness (Fahr, Podsakoff, \& Organ, 1990). Third, ethical leaders also express a concern for people and serve as role models for others. Such concern for others and role modeling is highly similar to other forms of positive leadership such as individualized and idealized influence, both of which have been related to ratings of supervisor effectiveness (Judge \& Piccolo, 2004). Brown et al. (2005) found that ethical leadership was positively related to ratings of supervisory effectiveness. Fourth, it is reasonable to presume that superiors care about ethics and want to promote it within their organizations. Even though cynical attitudes toward business leaders are prevalent (Bateman, Sakano, \& Fujita, 1992), research suggests that senior leaders care deeply about ethics and social responsibility (Weaver, Treviño, \& Cochran, 1999). Therefore, it is likely that superiors value ethical leadership as a critical criterion for promotability within their organizations. 
In sum, ethical leadership has been explicitly put forth as a positive form of leadership influence (Brown et al., 2005; Detert et al., 2007) and the extant research consistently links positive leadership to increases in leader performance. Thus, it stands to reason that leaders who engage in ethical leader behavior send strong signals of their suitability to fill higher level leadership positions. Based on the logic and research described above, we offer the following hypothesis.

Hypothesis 1. Ethical leader behavior is positively associated with leader promotability.

Leadership is certainly not performed in a vacuum and the context in which leaders exist may greatly impact their ability to influence important outcomes. Germane to the study of ethical leadership is that of the prevailing ethical culture. Ethical culture represents the formal and informal systems of behavioral control which reinforce ethical or unethical behavior (Treviño, 1990). Thus, ethical culture represents formal policies and procedures, ethical norms, authority structures, and reward systems. Accordingly, the extent to which "cultural systems support ethical conduct, individual behavior is expected to be more ethical" (Treviño, Butterfield, \& McCabe, 1998: 452). Ethical cultures then often establish what is deemed legitimate and acceptable behavior in organizations and thereby inform employee actions and decisions.

Research has shown that ethical culture functions as a positive influence on organizational members' perceptions and behavior. Ethical culture involves a range of collective organizational behavior such as heightened transparency, support of employee needs, open ethical communication, and ethical clarity (Kaptein, 2008). Most germane to the present study is the dimension of ethical culture that deals with the degree to which ethical leader behavior is rewarded and unethical behavior punished by management, also known as "ethical environment" (Treviño et al., 1998) or "sanctionability" (Kaptein, 2008). Here, rewards and punishments related to ethical behavior serve to shape the meaning of organizational behavior by establishing behavioral norms and expectations. As Treviño, Weaver, Gibson, and Toffler remarked, "discipline for rule violators serves an important symbolic role in organizations - it reinforces standards" and "upholds the value of conformity to shared norms" (Treviño, Weaver, Gibson, \& Toffler, 1999: 139). In this regard, ethical cultures reinforce perceptions that certain ethical practices are desired while other actions are undesirable, even punishable. Of course responsibility for establishing and maintaining ethical culture often lies with senior management and thus the effects of such culture are felt most by junior and mid-level managers.

Based on the above research, we argue that an ethical culture or environment may serve to strengthen the relationship between ethical leader behavior and leader promotability. In highly ethical cultures, adherence to ethical norms becomes increasingly important to rewards for such behavior. Conversely, deviance from ethical norms is associated with contingent punishments (Brown \& Treviño, 2006). Remaining consistent with the prevailing culture, superiors may be more likely to recognize ethical components of leadership through the formal reward system; thereby, rewarding leaders for their adherence to ethical norms. Therefore, ethical 
cultures serve to amplify and make more salient the positive influence of ethical leader behavior on supervisory perceptions of leader capabilities for higher levels of management. Hence, we contend that ethical culture will strengthen the relationship between ethical leader behavior and leader promotability.

Hypothesis 2 . The relationship between ethical leader behavior and leader promotability is moderated by ethical culture such that the relationship is more strongly positive within a more ethical culture.

Another contextual factor that is pertinent to ethical leader behavior and leader promotability derives from the performance contingencies under which leaders work. That is, leader promotability is not simply based upon whether he/she behaves in an ethical manner, but also whether business results are achieved. Indeed when one examines research on "derailed" high-potential managers, failure to meet business objectives is often a key theme (Lombardo et al., 1987). Such pressure to achieve results is prevalent in many organizations as indicated in one national survey whereby 60 percent of American workers reported feeling performance pressure on the job (Petry, Mujica, \& Vickery, 1998). When considering the extent to which ethical leadership is associated with promotability, pressure to achieve results may serve as an important contextual moderator.

As argued previously (Hypothesis 1), ethical leadership is valued by supervisors (Weaver et al., 1999) and provides important signals about the suitability for promotion (Spence, 1973). We purport however that signals sent by leaders about ethical leadership and suitability for promotion are substantially shaped by contexts of high pressure to achieve results. It has long been recognized that context serves to modify both the occurrence and meaning of specific organizational behavior (Johns, 2006). As such, a context of pressure to achieve results is likely to impinge upon the display and value of ethical leadership in relationship to judgments of promotability. Indeed, pressured contexts have been linked with increases in unethical behavior (Robertson \& Rymon, 2001; Treviño, Weaver \& Reynolds 2006). Thus, in such a context where unethical behavior may be more likely (Robertson \& Rymon, 2001), leaders who choose to uphold ethical standards may be seen as more suitable to face the ethical challenges associated with higher-level and more visible organizational roles. High pressure contexts then may serve to amplify the signals sent to superiors about a leader's commitment to ethical leadership (Spence, 1973) in the face of strong competing behavioral choices. In contrast, in contexts where pressure to achieve results is less strong and where incidents of unethical behavior may be less prevalent, ethical leadership may play a diminished role in promotability judgments. That is, ethical leadership in such a context would send weaker signals regarding how leaders would respond to the difficult ethical challenges and behavioral choices that likely await them in senior management positions.

Put simply, leaders who demonstrate strong ethical leadership in the face of high pressure send a powerful signal to supervisors that they have the capabilities to effectively handle the myriad ethical challenges associated with ascending levels of responsibility. Likewise, leaders that have faced strong pressure to achieve and 
fallen short in their ethical leadership are likely to send the signal suggesting that they cannot be counted upon to provide a significant ethical example in future senior management roles. In short, we expect that the relationship between ethical leadership and promotability will be strengthened in higher pressure to achieve results environments as ethical leadership in such contexts is more salient and sends clearer signals about leaders' suitability for higher level leadership roles.

Hypothesis 3. The relationship between ethical leader behavior and leader promotability is moderated by pressure to achieve results such that the relationship is stronger under conditions of high pressure to achieve results.

\section{METHODS}

\section{Participants and Procedure}

Participants were 96 managers (focal leaders) and their 412 employees from two independent organizations; a multi-media organization and a national insurance organization. Both organizations participated as part of their ongoing leadership development efforts. The 96 focal leaders had a mean age of 40.19 (SD = 7.95), a mean organizational tenure of 5.35 years $(\mathrm{SD}=.69)$, and a mean of 16 years of education $(\mathrm{SD}=.75)$. The average number of employees rating each leader's ethical leadership was $5.74(\mathrm{SD}=3.90)$. Employees reporting to these managers had a mean age $41.5(\mathrm{SD}=8.1)$, a mean organization tenure of $10.09(\mathrm{SD}=6.7)$, and were primarily female (65 percent).

Data were collected in two waves in the late autumn of 2006. First, 19 vice presidents who supervised the 96 focal leaders were sent a short paper-and-pencil evaluation form containing the measures of leader promotability and job performance. These 19 vice presidents had an average age of 47, worked for their current organization for 5.30 years $(\mathrm{SD}=1.25)$ and reported average of 14.83 years $(\mathrm{SD}$ $=9.08$ ) managerial experience. To ease this process, we included the names of managerial direct reports on the evaluation form and encouraged the vice presidents to delete the names of any listed focal leaders who were not currently under their supervision and to add the names of unlisted employees who were currently under their supervision. The remaining study data were collected via a web-based survey sent to all participating managers and employees. All survey items were rated using a 5-point Likert-type scale ranging from 1 (strongly disagree) to 5 (strongly agree) with a middle-point defined as 3 (neither agree nor disagree) unless otherwise noted.

\section{Measures}

Ethical Leader Behavior

We used the ten-item Ethical Leadership Survey (ELS) developed by Brown et al. (2005) to measure the ethical leader behavior of each focal leader. Each focal leader's direct reports completed the ELS. Brown et al. (2005) report a series of construct validity studies demonstrating strong psychometric properties of the ELS including 
adequate reliability and confirmation of their theoretical one-factor model. In addition, because our interest was in each focal leader's overall level of ethical leader behavior, we aggregated employee ratings to their respective leader. Aggregating employee ratings requires justification of within-group agreement. James, Demaree, and Wolf (1984) noted that the $r_{w g}$ statistic provides a valid estimate of actual within-group agreement, and that an $r_{w g}$ equal to or greater than .70 demonstrates acceptable levels of agreement. Following previous research (Grawitch \& Munz, 2004) we calculated an $r_{w g}$ for each focal leader's group. Results indicated a mean $r_{w g}$ of .97 and showed that none of the $r_{w g}$ coefficients fell below .70. These results support the aggregation of employees' ratings to their respective leader. Sample items read: "Disciplines employees who violate ethical standards" and "Sets an example of how to do things the right way in terms of ethics."

\section{Ethical Culture}

Ethical culture was measured using the 5-item scale developed by Hunt, Wood, and Chonko (1989). The instrument assesses employee perceptions of the extent to which managers within the organization behave ethically, are concerned about ethics, and whether ethical behavior is rewarded or punished. We calculated $r_{w g}$ for each focal leader's work group and results indicated a mean $r_{w g}$ of .87. This result supports the aggregation of employees' ratings to their respective focal leader's work group. Sample items read: "managers in my company often engage in behaviors that I consider to be unethical" and "top management in my company has let it be known in no uncertain terms that unethical behaviors will not be tolerated."

Pressure to Achieve Results

A 3-item scale was developed for the present study to measure pressure to achieve results. This measure captured focal leaders' perceptions of organizational pressure to achieve results for their units particularly those that are financial in nature. Sample items read: "There is a great deal of pressure to perform here" and "The most important part of performance here is making the numbers."

\section{Leader Promotability}

Previous work has defined promotability as the "favorability of an employee's advancement prospects" (Greenhaus et al., 1990: 69). To capture this concept we measured a focal leaders' near-term promotability with one item tapping a leader's promotional prospects which read, "In the next twelve months, this manager will likely be promoted" (Shore, Cleveland, and Goldberg, 2003). In addition, some scholars have noted that when thinking about filling future roles in organizations, supervisors may also consider a leader's capacity to perform at higher levels beyond their immediate role (DePater et al., 2009). Thus, we measured focal leaders' promotability to senior leadership with a single item that read, "This manager is likely to reach the highest levels of management" (Shore et al., 2003). Senior vice presidents rated both items using a 7-point Likert-type scale ranging from 1 (strongly disagree) to 7 (strongly agree) with a middle-point defined as 4 (neither agree nor disagree). 


\section{Control Variables}

Because this study involves ratings of ethical leader behavior, we sought to control for the possibility that ratings of ethical leadership might be confounded with focal leaders' level of job performance. Thus, we controlled for each focal leader's overall job performance as rated by his or her senior vice president using two items from Williams and Anderson's (1991) measure of job performance. These items read, "Meets formal performance requirements of the job" and "Performs tasks that are expected of him/her." These items were rated using a 7-point Likert-type scale ranging from 1 (strongly disagree) to 7 (strongly agree) with a middle-point defined as 4 (neither agree nor disagree).

In addition, previous research has shown that other forms of leader behavior may contain an ethical component and thus would serve to confound the true effects of ethical leader behavior. Of these other forms of leader behavior, the idealized influence dimension of transformational leadership has been supported as having an ethical component (Brown et al., 2005). Leaders who engage in idealized influence may be seen as "role models for followers to emulate" and they "can be counted on to do the right thing" and they demonstrate "high standards of ethical and moral conduct" (Avolio, 1999: 43). To control for the influence of this dimension of effective leadership on promotability, we measured idealized influence using a 3-item measure of "role modeling" contained within the Transformational Leadership Inventory (Podsakoff, MacKenzie, Moorman, \& Fetter, 1990). Finally, our data were derived from two organizations. To control for potential differences between these organizations, we included a dummy coded variable in our analyses.

\section{RESULTS}

Prior to hypothesis testing, we conducted a confirmatory factor analysis (CFA) of the predictor constructs (ethical leader behavior, ethical culture, and pressure to achieve results). Results from this CFA showed an adequate fit for a three-factor model $\left(\chi^{2}=220.08, p<.01 ;\right.$ SRMR $\left.=.08, \mathrm{CFI}=.90, \mathrm{NNFI}=.91\right)$, providing evidence of the distinctiveness of these constructs. In addition, the three-factor model displayed significantly better fit to the data than a one-factor model $\left(\Delta \chi^{2}=179.51\right.$ $[3], p<.01$; SRMR $=.17, \mathrm{CFI}=.69$, NNFI $=.65)$. The means, standard deviations, correlations, and reliability estimates for all study variables are reported in Table 1. Ethical leader behavior was significantly and positively related to promotability to senior leadership $(r=.23, p<.05)$, but not to near-term promotability $(r=.09$, $n s)$. Ethical culture was significantly and positively correlated with both leader promotability variables. Pressure for results was significantly and negatively related to leader near-term promotability $(r=-.21, p<.05)$ and promotability to senior leadership $(r=-.27, p<.05)$. As for the two control variables, job performance did not display a significant relationship with leader ethical behavior, but consistent with previous research, was significantly and positively associated with the leader promotability variables (DePater et al., 2009). Role modeling was significantly and positively related to ethical leader behavior, but was not significantly associated with the leader promotability variables. 
Table 1: Means, Standard Deviations, and Correlations ${ }^{\mathrm{a}, \mathrm{b}}$

\begin{tabular}{|c|c|c|c|c|c|c|c|c|c|c|}
\hline Variables $^{c}$ & Mean & s.d. & 1 & 2 & 3 & 4 & 5 & 6 & 7 & 8 \\
\hline 1. Organization & .57 & .49 & - & & & & & & & \\
\hline $\begin{array}{l}\text { 2. Near-term } \\
\text { Promotability }\end{array}$ & 3.27 & 2.02 & .09 & - & & & & & & \\
\hline $\begin{array}{l}\text { 3. Promotability to } \\
\text { Sr. Leadership }\end{array}$ & 2.63 & 1.93 & .01 & $.67 * *$ & - & & & & & \\
\hline $\begin{array}{l}\text { 4. Job } \\
\text { performance }\end{array}$ & 6.08 & 0.91 & -.12 & $.20 *$ & $.21 *$ & .87 & & & & \\
\hline 5. Role modeling & 3.71 & 0.67 & $-.22 *$ & .04 & .17 & .17 & .93 & & & \\
\hline $\begin{array}{l}\text { 6. Ethical leader } \\
\text { behavior }\end{array}$ & 4.05 & 0.47 & -.18 & .09 & $.23 *$ & .15 & $.86^{* *}$ & .95 & & \\
\hline 7. Ethical culture & 3.79 & 0.43 & -.04 & $.22 *$ & $.37 * *$ & $22 *$ & $.31 * *$ & $.38 * *$ & .84 & \\
\hline $\begin{array}{l}\text { 8. Pressure to } \\
\text { achieve results }\end{array}$ & 3.10 & 0.85 & .15 & $-.21^{*}$ & $-.27 *$ & -.05 & .10 & .11 & -.17 & .80 \\
\hline
\end{tabular}

${ }^{\mathrm{a}} \mathrm{N}=96$

${ }^{\mathrm{b}}$ Coefficient alphas are presented along the diagonal.

${ }^{\mathrm{c}}$ Organization was dummy coded $(0,1)$; variables $2-4$ were derived from each focal leader's senior vice president; variables 5-7 derived from each focal leader's direct reports; variable 8 derived from focal leader.

In order to test the study hypotheses, we conducted two hierarchical regression analyses, one corresponding to each leader promotability variable. Relevant control variables were entered first into each model, followed second by ethical leader behavior, ethical culture, and pressure to achieve results. The last step entered the interaction terms testing moderation effects of ethical culture and pressure to achieve results. Variables were first mean-centered prior to creating the required interaction terms for the regression models.

Hypothesis 1 posited ethical leader behavior to be positively associated with leader promotability. As shown in Table 2, after controlling for organization, role modeling, and job performance ethical leader behavior was a significant predictor of promotability to senior leadership $(\beta=.26, p<.05)$, but not of near-term promotability $(\beta$ $=.20, n s)$. These findings provide partial support for Hypothesis 1 and indicate that leaders who engage in ethical leader behavior are more likely to be rated by their superiors as having increased prospects to reach the highest levels of management, but not necessarily as being promotable in the short term.

Beyond positing a direct relationship between ethical leader behavior and leader promotability outcomes, we predicted that ethical culture would moderate these relationships (Hypothesis 2). From Table 2, the interaction term was a significant predictor of promotability to senior leadership $(\beta=.34, p<.01)$ but not near-term promotability $(\beta=.13, n s)$. Thus, these results provide partial support for Hypothesis 2. Following the recommendations of Aiken and West (1991), we used split-plot analyses to better understand the nature of the significant moderation between ethical culture and ethical leader behavior. The split-plot showed that in conditions represented by higher ethical culture, leaders engaging in stronger ethical leader behavior 
Table 2: Hierarchical Regression Results ${ }^{\mathrm{a}}$

\begin{tabular}{|c|c|c|}
\hline Variable & $\begin{array}{l}\text { Near-term } \\
\text { Promotability }\end{array}$ & $\begin{array}{l}\text { Promotability to } \\
\text { Senior Leadership }\end{array}$ \\
\hline \multicolumn{3}{|l|}{ Step 1} \\
\hline Organization & .13 & .07 \\
\hline Role modeling & .03 & .15 \\
\hline Job performance & $.21^{* *}$ & $.20 *$ \\
\hline$R^{2}$ & .05 & $.06^{*}$ \\
\hline \multicolumn{3}{|l|}{ Step 2} \\
\hline Organization & .17 & .09 \\
\hline Role modeling & -.13 & -.12 \\
\hline Job performance & $.17 *$ & .14 \\
\hline Ethical leader behavior & .19 & $.26^{*}$ \\
\hline Ethical culture & .11 & $.25^{* *}$ \\
\hline Pressure to achieve results & $-.28 * *$ & $-.20 * *$ \\
\hline$R^{2}$ & $.16^{* *}$ & $.21^{* *}$ \\
\hline$\Delta R^{2}$ & $.11^{* *}$ & $.15^{* *}$ \\
\hline \multicolumn{3}{|l|}{ Step 3} \\
\hline Organization & $.18 *$ & .11 \\
\hline Role modeling & -.08 & -.01 \\
\hline Job performance & $.18 *$ & .15 \\
\hline Ethical leader behavior & .20 & $.26^{*}$ \\
\hline Ethical culture & .10 & $.22 *$ \\
\hline Pressure to achieve results & $-.26 * *$ & -.15 \\
\hline Ethical leader behavior $\mathrm{x}$ Ethical culture & .13 & $.34 * *$ \\
\hline Ethical leadership behavior $\mathrm{x}$ Pressure to achieve results & .07 & $.20 *$ \\
\hline Total $R^{2}$ & $.18^{* *}$ & $.30^{* *}$ \\
\hline$\Delta R^{2}$ & .02 & $.09 * *$ \\
\hline
\end{tabular}

\footnotetext{
${ }^{a}$ Parameter estimates are standardized; tests are one-tailed.

$* p<.05$

$* * p<.01$
}

were more likely to receive increased ratings of promotability to senior leadership than those in conditions represented by lower ethical cultures (see Figure 1).

Hypothesis 3 predicted that pressure to achieve results would moderate the relationships between ethical leader behavior and leader promotability outcomes. 
Results in Table 2 show the interaction term as a significant predictor of promotability to senior leadership $(\beta=.20, p<.05)$, but not near-term promotability $(\beta=$ $.07, n s)$, providing partial support for Hypothesis 3. Figure 2 displays the form of the significant interaction, indicating that in contexts represented by increased pressure to achieve results, higher ethical leader behavior is strongly related to ratings of a leader's promotability to senior leadership while lower ethical behavior was associated with significantly lower ratings of promotability to senior leadership.

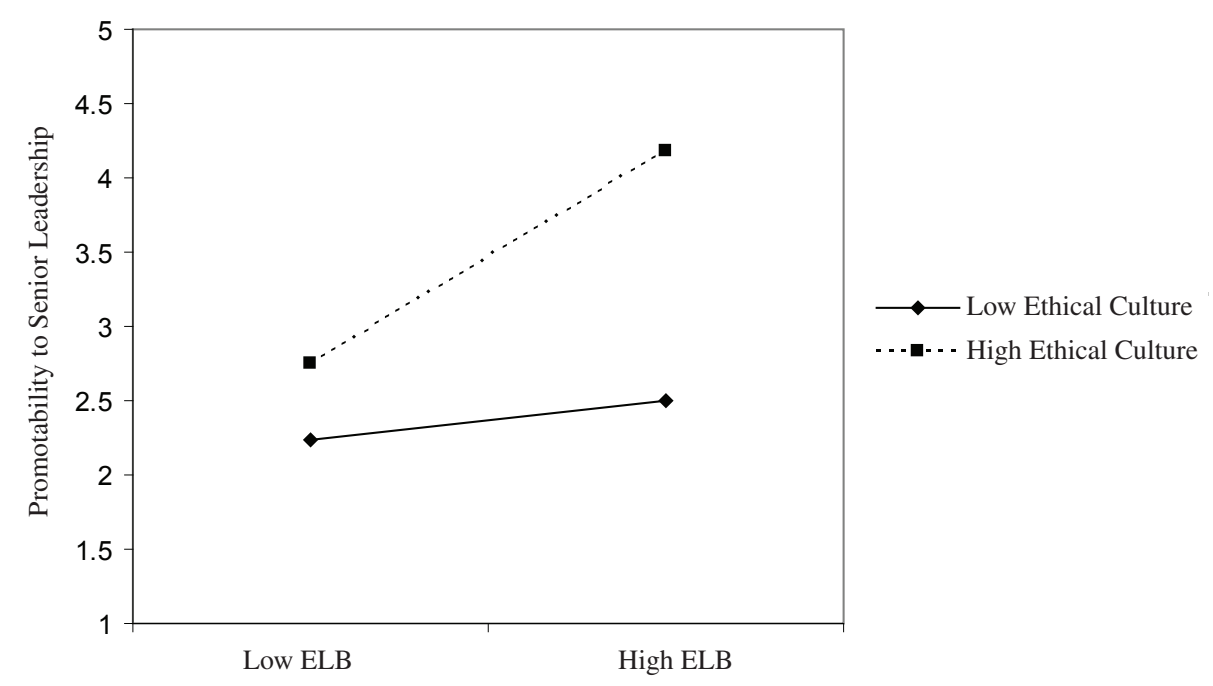

Figure 1: Interactive Effects of Ethical Culture and Ethical Leadership Behavior on Leader Promotability to Senior Leadership ${ }^{\mathrm{a}}$

${ }^{\mathrm{a}} \mathrm{ELB}=$ Ethical Leader Behavior

\section{DISCUSSION}

The goal of the current study was to examine the influence of ethical leader behavior on leader promotability. We argued that ethical leader behavior would demonstrate significant positive effects on leader promotability. In addition, we explored the context surrounding this relationship arguing that ethical culture and pressure to achieve results would serve to moderate the relationship between ethical leadership and promotability. The results provided support for the contention that ethical leader behavior positively influences leader promotability. Broadly speaking, we were able to account for significant variance in ratings of promotability to senior leadership (30 percent). In addition, we found that ethical culture and pressure to achieve results moderate the relationship between ethical leader behavior and judgments of promotability to senior leadership roles.

More specifically, results indicate that leaders who engage in a high level of ethical leadership were increasingly likely to be rated as having potential to attain the highest levels of management. Despite their increased likelihood of being seen as having significant potential, ethical leaders in our sample were not any more likely 


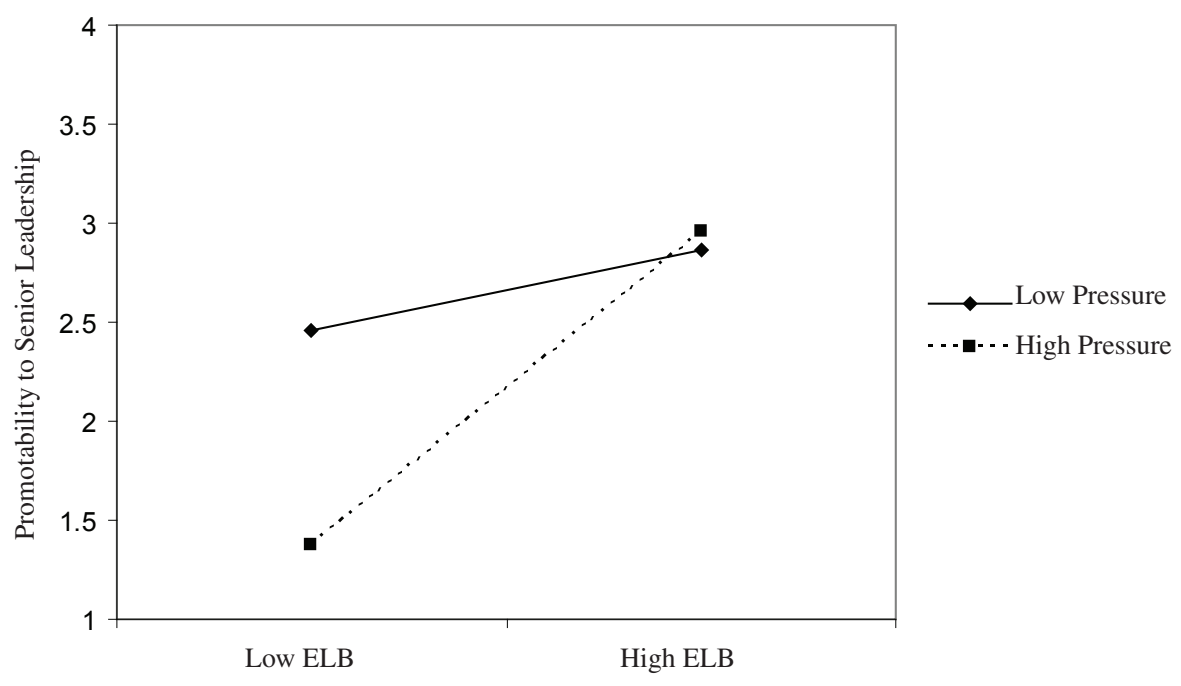

Figure 2: Interactive Effects of Pressure to Achieve Results and Ethical Leadership Behavior on Leader Promotability to Senior Leadership ${ }^{\mathrm{a}}$

${ }^{\mathrm{a}} \mathrm{ELB}=$ Ethical Leader Behavior

to be seen as promotable in the near-term. In other words, leaders that engaged in high levels of ethical leader behavior were seen as having high potential for senior leadership roles but were not seen as being more promotable in the immediate future. These findings give way to more questions than answers about the mechanisms at play between ethical leadership behavior and the associated consequences for leaders themselves. One plausible explanation is that ethical leader behavior functions as a baseline or necessary condition for promotion judgments, but is not a sufficient condition. Our data lend some support to this idea in that correlations reveal a positive relationship between leader job performance and near-term promotability and no relationship between ethical leader behavior and job performance. In this sense, leader job performance depends on many factors and ethical behavior may be a supportive rather causal mechanism. Some however, might view the present results as suggestive of the existence of an "ethical ceiling" whereby succession systems fail, ultimately rewarding leaders who achieve the bottom line at all costs. If this were the case, we might expect to see a significant inverse relationship between ethical leader behavior and near-term promotability; however, our data show no relationship. Thus, although our data do not sufficiently test the existence of an "ethical ceiling" they do suggest that ethical leader behavior is not a primary factor in the near-term promotion of leaders in our sample.

Interestingly, the effects of ethical leadership on career mobility might not be evident until one reaches a higher level of management as ethical leadership becomes more important as leaders advance to higher levels. At higher levels of management, the responsibility to demonstrate ethical leadership and create a highly ethical culture is strongly encouraged by law (e.g., Sarbanes-Oxley's emphasis on ethical conduct among top executives; U.S. Federal Sentencing Guideline's emphasis on 
creating an ethical culture). It is also possible that in contexts similar to our study where overall ethical leadership levels are well above average and less variant than others (see Brown et al., 2005, for comparisons); ethical leadership may not provide a promotion advantage because almost all leaders in the competition for promotion have achieved an acceptable or base-line level of ethical proficiency. In such contexts, ethical leadership may help identify a leader with the potential to fulfill senior level roles but does not help him/her stand out among peers when more near-term promotions are on the line. Finally, the non-findings for near-term promotability may simply be representative of the well known disconnect between stated organizational expectations of behavior and behavior which is actually rewarded (Kerr, 1975). Regardless, future research is needed to explore the above conjectures.

Our results also present the striking augmentation in outcomes due to ethical culture. Ethical cultures have been purported to provide the critical guiding context for individuals' engagement in ethical behavior. In theory, ethical cultures establish the normative structures that should provide increased encouragement and support for the performance of ethical behavior and the reduction of unethical behavior. The present results support the notion that a highly ethical culture bolsters the potency of positive influences stemming from ethical leadership. That is, highly ethical cultures provide an environment in which leaders' superiors may pay significantly more attention to their subordinate leaders who engage in ethical leader behavior. Specifically, our findings showed that within ethical cultures, leaders who display high levels of ethical leader behavior receive significantly higher ratings of promotability to senior leadership from their superiors. This finding is supportive of arguments that an organization's ethical culture can encourage ethical conduct and supports the maintenance of ethical leadership (Brown \& Treviño, 2006). Indeed, our results may suggest that ethical culture heightens superiors' attention to the ethical behavior of their subordinate leaders and thereby increasing the evaluative distance in promotability to senior leadership ratings between leaders who engage in ethical behavior and those who do not. It should be noted, however, that despite this moderating effect of culture on leader potential ratings, the presence of a highly ethical culture did not influence ratings of leader near-term promotability. Although ethical culture is positively correlated with near-term promotability, culture does not appear to interact with ethical leader behavior in a way that produces noticeable gains in supervisory ratings. In all, these results reveal the potency of ethical culture in amplifying the positive effects of ethical leadership.

We also found a significant moderating effect of pressure to achieve results. We argued that in environments where there is a great deal of pressure to achieve results, a leader's ethical behavior is likely to serve as a strong signal upon which supervisors determine suitability for higher level roles. The present results confirm that in high pressure contexts, the relationship between ethical leadership and ratings of promotability to senior leadership is amplified. However, it is interesting to note the pattern of this moderating effect. Specifically, as ethical leadership increases, leader promotablity to senior leadership appears to be rather similar regardless of the level of pressure to achieve results. Under conditions of lower ethical leadership, a leader's promotability to senior leadership is diminished in high pressure contexts 
compared to low pressure ones. Thus, one could interpret our results as demonstrating the potential career derailing effect of weak ethical leadership in high pressure contexts. However, as noted above, what qualifies as low ethical leadership in this study is actually quite average compared to other studies using the same measurement approach (Brown et al., 2005). It appears that even "average" ethical leadership can be seen as signal of incapability in high pressure contexts. Thus, the present results reveal that there may be substantial rewards for leaders who despite such pressure to achieve find ways to display above average levels of ethical leadership.

When considering the findings of this study, it is important to keep in mind that job performance was controlled in the analyses. In other words, ethical leadership is associated with leader promotability to senior leadership, but only when job performance is held constant. Post-hoc analyses revealed that ethical leadership did not significantly predicted promotability to senior leadership when the control for job performance was eliminated from the regression model. That is, ethical leadership is related to promotability to senior leadership but only when similar levels of job performance are considered. Clearly, few organizations would be willing to advance a leader (no matter how ethically strong he/she may be) without taking into account his/her job performance (DePater et al., 2009). Further, it is important to note that the pressure to achieve results measure represents the focal leader's perception of achieving results. It does not indicate that financial performance is the only important goal or that superiors agree that results are most important. Indeed, research has shown that the perceptions of senior leaders and rank and file employees of an organization's ethical environment are somewhat different (Treviño, Weaver, \& Brown, 2008) in that employees hold more negative views. As such, our findings might also be explained by such differences in perception. Superiors want their managers to be strong ethical leaders; however, that message is not always clearly articulated to lower level managers. Overall, our findings suggest superiors do value ethical leadership and that to "get ahead" in a high pressured environment a leader must not construe his/her behavioral choices in terms of "results" versus "ethics" but rather how to achieve results while engaging in ethical behavior. From senior management's perspective, the findings may also highlight the fact that creating a "high-performance" environment with some pressure to achieve could be a key contributor to eliciting ethical leadership.

\section{Developing Ethical Leadership}

From a practical standpoint, our results contribute much needed evidence to what has remained a largely anecdotal discussion of the importance of ethical leadership. Viewed from an organizational perspective, the present findings demonstrate the imperative of improving the ethical components of positive leadership development efforts. To date however, organizational leadership development programs are generally geared toward developing functional and interpersonal proficiency, ignoring skills for navigating political and ethically ambiguous cultures or developing the moral facets (May, Chan, Hodges, \& Avolio, 2003) and role obligations (Werhane, 1985) of ethical leadership. Although a lengthy discussion about whether 
or not ethics can be taught are beyond the scope of this study, previous research has demonstrated that positive forms of leader behavior can be learned (Barling, Weber, \& Kelloway, 1996). Further, focusing on the behavioral aspects of ethical leadership is likely to net far greater change in managerial behavior than attempts to mold attitudes or morals (Bommer, Rubin, \& Baldwin, 2004; Rubin, Dierdorff, Bommer, \& Baldwin, 2009). As such, the present study provides evidence to make the career-related business case for leaders to become involved in development programs geared toward inculcating the performance of ethical leader behavior. Along these lines, it is worth noting that development of the ethical leadership scale by Brown and colleagues (2005) and its associated findings may serve as a behavioral scorecard by which leaders measure their ultimate improvement. In this sense ethical leadership is judged against a behavioral standard rather than one based on personal values, morals, or attitudes, which are often more difficult to shape.

Moreover, the present results are important for leaders themselves who may demonstrate little motivation to develop the ethical dimensions of leadership for fear of little return on their development efforts. Our results should increase the motivation to engage in ethical leadership development; motivation which has been linked to increases in the ultimate efficacy of development programs (Colquitt, LePine, \& Noe, 2000). Further, research on transfer of training to the job has found that contextual factors such as an ambiguous ethical culture can easily counteract the effects of development programs. In contrast, a favorable context can enhance even suboptimal training (Baldwin \& Magjuka, 1997; Rouiller \& Goldstein, 1993). Given the present findings, any effort to develop ethical leadership is likely to be strengthened by the existence or concurrent development of a highly ethical culture. In all, the present findings provide relatively good news and support for the old adage that "good ethics is good business" such that ethical behavior serves to benefit a leader him/herself.

\section{Boundary Conditions and Future Directions}

Although this study presents some compelling findings and possesses some positive methodological strengths (e.g., multiple data sources, two independent organization samples, controls for leader role modeling and performance, etc.), a few limitations deserve discussion. First, this study employed a cross-sectional design making the direction of causality difficult to decipher. It is possible that the outcomes in this study have a reverse or reciprocal influence on ethical leader behavior. For example, it could be that when leaders are given positive feedback about their behavior that they are more likely to behave in an ethical manner. Second, we measured leaders' superiors' evaluations of promotability to senior leadership and near-term promotion, not actual promotions which would require longitudinal data. Third, the leader promotability outcomes represent subjective appraisals. As previous research has noted, subjective and objective measures are not equivalent (Bommer, Johnson, Rich, Podsakoff, \& MacKenzie, 1995). However, we did attempt to mitigate this subjectivity by controlling for ratings of role modeling and leader performance. Despite these controls we were not able to capture the actual cognitive decision-making tactics 
supervisors used to arrive at their judgments of focal leader promotability. Finally, the scale used to measure pressure to achieve results was developed for the present study. Although the items displayed adequate psychometric properties, the measure's overall construct validity in relation to other similar measures is unknown.

Looking toward the future, a number of fruitful avenues for research exists. One particularly salient area is objective performance outcomes of ethical leader behavior. It remains to be determined whether ethical leader behavior pays-off in terms of objective task-related performance outcomes. Conventional wisdom seems to imply that in fact ethical leadership is not necessarily the most efficient way to achieve performance standards (Veiga, Golden, \& Dechant, 2004). Testing whether ethical leadership relates to these more primary performance outcomes seems critical towards ultimately influencing and eliciting ethical organizational behavior. In addition, we echo Brown and Treviño (2006) who proposed examining prosocial behavior of leaders such as organizational citizenship behavior. Such behavior has been shown to be highly discretionary among employees and is influenced by the social environment (Bommer, Dierdorff, \& Rubin, 2007). Recent research is beginning to establish such links between ethical leadership and citizenship (Mayer et al., 2009).

An additional area to investigate is whether a focal leader's level of management moderates the relationship between ethical leadership and near-term promotability. For example, executive ethical leaders spend considerably more time dealing with important non-employee stakeholders outside the organization whereas lower-level managers spend the majority of time with employees, their immediate stakeholders (Brown \& Treviño, 2006). Similarly, the ethical leadership of superiors is likely to be an important moderator. If the focal leader's boss is a strong ethical leader, it is likely that he/she will place greater value on ethical leadership as a criterion for promotability. Finally, we expect that the level of ethical leadership among other candidates for promotion will impact the connection between ethical leadership and promotion. In the present study sample, the mean value of ethical leadership indicated a strong level of ethical leadership. If all candidates for promotion display relatively high levels of ethical leadership, then any ethical leadership "advantage" may be somewhat neutralized. On the other hand, a candidate who has demonstrated significantly strong ethical leadership compared to his/her peers, could have an advantage in the competition for promotion.

Another important line of inquiry to explore is that of antecedents to ethical leader behavior and their ultimate influence on leader outcomes. As noted by others (Rubin et al., 2009; Rubin, Munz, \& Bommer, 2005) antecedents to effective leadership have been greatly understudied yet represent the building blocks of understanding motivated behavior such as ethical leadership. Aside from personal characteristics that have been proffered in the literature, we would expect that leaders' perceptions about their work environment would serve as primary input into performing ethical leadership. For example, a manager's perceptions of organizational justice may significantly determine whether or not he/she engages in ethical leader behavior. Similarly, leader role expectations (Dierdorff \& Rubin, 2007) as they relate to engaging ethical behavior may impact whether leaders view ethics as part of their 
core work role. Finally, work needs to be completed to help explain why ethical leader behavior is associated with particular outcomes. That is, future explorations should be focused on the mediating mechanisms that describe how ethical leader behavior is ultimately transmitted to leader outcomes. Engaging in these types of studies would add considerable knowledge to the growing empirical literature on ethical leadership. We hope the present study serves as a partial building block for future examinations of this fundamental topic.

\section{ACKNOWLEDGMENTS}

This study was supported in part by the Wicklander Fellowship in Business Ethics and the Institute for Business and Professional Ethics, DePaul University. A version of this paper was presented at the 2008 Academy of Management Meeting, Anaheim, California.

\section{REFERENCES}

Aiken, L. S., \& West, S. G. 1991. Multiple regression: Testing and interpreting interactions. Newbury Park, CA: Sage.

Ashkanasy, N. M., Windsor, C. A., \& Treviño, L. K. 2006. Bad apples in bad barrels revisited: Cognitive moral development, just world beliefs, rewards, and ethical decision-making. Business Ethics Quarterly, 16: 449-73.

Avolio, B. J. 1999. Full leadership development: Building the vital forces in organizations. Thousand Oaks, CA: Sage Publications.

Baldwin, T. T., \& Magjuka, R. 1997. Training as an organizational episode: Pre-training influences on trainee motivation. In J. K. Ford (Ed.), Improving training effectiveness in work organizations, 99-127. Mahwah, NJ: Lawrence Erlbaum Publishers.

Barling, J., Weber, T., \& Kelloway, E. K. 1996. Effects of transformational leadership training on attitudinal and financial outcomes. Journal of Applied Psychology, 81: 827-32.

Bass, B. M. 1990. Handbook of leadership. New York: The Free Press.

Bateman, T. S., Sakano, T., \& Fujita, M. 1992. Roger, me, and my attitude: Film propaganda and cynicism toward corporate leadership. Journal of Applied Psychology, 77: $768-71$.

Bommer, W. H., Dierdorff, E. C., \& Rubin, R. S. 2007. Does prevalence mitigate relevance? The moderating effect of group-level OCB on employee performance. Academy of Management Journal, 50: 1481-94.

Bommer, W. H., Johnson, J. J., Rich, G. A, Podsakoff, P. M., \& MacKenzie, S. B. 1995. On the Interchangability of subjective and objective measures of employee performance: A meta-analysis. Personnel Psychology, 48: 587-605.

Bommer, W. H., Rubin, R. S., \& Baldwin, T. T. 2004. Setting the stage for effective leadership: Antecedents of transformational leadership behavior. The Leadership Quarterly, 15: 195-210.

Brown, M. E., \& Treviño, L. K. 2006. Ethical leadership: A review and future directions. The Leadership Quarterly, 17: 595-616. 
Brown, M. E., Treviño, L. K., \& Harrison, D. 2005. Ethical leadership: A social learning perspective for construct development and testing. Organizational Behavior and Human Decision Processes, 97: 117-34.

Colquitt, J. A., LePine, J. A., \& Noe, R. A. 2000. Toward an integrative theory of training motivation: A meta-analytic path analysis of 20 years of research. Journal of Applied Psychology, 85: 678-707.

Combs, J. G., Liu, Y., Hall, A. T., \& Ketchen, D. J. 2006. How much do high performance work practices matter? A meta-analysis of their effects on organizational performance. Personnel Psychology, 59: 501-28.

DePater, I. E., Van Vianen, A. E. M., Bechtoldt, M. N., \& Klehe, U. C. 2009. Employees' challenging job experiences and supervisors' evaluations of promotability.Personnel Psychology, 62: 297-325.

Detert, J. R., Treviño, L. K., Burris, E. R., \& Andiappan, M. 2007. Managerial modes of influence and counterproductivity in organizations: A longitudinal business-unitlevel investigation. Journal of Applied Psychology, 92: 993-1005.

Dierdorff, E. C., \& Rubin, R. S. 2007. Carelessness and discriminability in work role requirement judgments: Influences of role ambiguity and cognitive complexity. Personnel Psychology, 60: 597-625.

Dierdorff, E. C., Rubin, R. S., \& Morgeson, F. P. 2009. The milieu of management: Exploring the context of managerial work role requirements. Journal of Applied Psychology, 94: 972-88.

Fahr, J. L., Podsakoff, P. M., \& Organ, D. W. 1990. Accounting for organizational citizenship behavior: Leader fairness and task scope versus satisfaction. Journal of Management, 16: 705-21.

Grawitch, M. J., \& Munz, D. C. 2004. Are your data nonindependent? A practical guide to evaluating nonindependence and within-group agreement. Understanding Statistics, 3: 231-57.

Greenhaus, J. H., Parasuraman, S., \& Wormley, W. M. 1990. Effects of race on organizational experiences, job performance evaluations, and career outcomes. Academy of Management Journal, 33: 64-86.

Hegarty, W. H., \& Sims, H. P. 1978. Some determinants of unethical decision behavior: An experiment. Journal of Applied Psychology, 63: 451-547.

Hogan, R., Curphy, G. J., \& Hogan, J. 1994. What we know about leadership: Effectiveness and personality. American Psychologist, 49: 493-504.

Howard, A., \& Bray, D. W. 1988. Managerial lives in transition: Advancing age and changing times. New York: Guilford Press.

Hunt, S. D., Wood, V. R., \& Chonko, L. B. 1989. Corporate ethical values and organizational commitment in marketing. Journal of Marketing, 53: 79-90.

James, L., Demaree, R., \& Wolf, G. 1984. Estimating within-group interrater reliability with and without response bias. Journal of Applied Psychology, 69: 85-98.

Johns, G. 2006. The essential impact of context on organizational behavior. Academy of Management Review, 31: 386-408. 
Judge, T. A., \& Piccolo, R. F. 2004. Transformational and transactional leadership: A metaanalytic test of their relative validity. Journal of Applied Psychology, 89: 755-68.

Kaptein, M. 2008. Developing and testing a measure for the ethical culture of organizations: The corporate ethical virtues model. Journal of Organizational Behavior, 29: $923-$ 47.

Kerr, S. 1975. On the folly of rewarding a while hoping for b. Academy of Management Journal, 18: 769-83.

Kerr, S., \& Jermier, J. M. 1978. Substitutes for leadership: Their meaning and measurement. Organizational Behavior and Human Performance, 22: 375-403.

Lombardo, M. M., Ruderman, M. N., \& McCauley, C. D. 1987. Explanations of success and derailment in upper-level management positions. Journal of Business \& Psychology, 2: 99-216.

Lowe, K. B., Kroeck, K. G., \& Sivasubramaniam, N. 1996. Effectiveness correlates of transformational and transactional leadership: A meta-analytic review of the MLQ literature. The Leadership Quarterly, 7: 385-425.

May, D. R., Chan, A. Y. L., Hodges, T. D., \& Avolio, B. J. 2003. Developing the moral component of authentic leadership. Organizational Dynamics, 32: 247-60.

Mayer, D. M., Kuenzi, M., Greenbaum, R., Bardes, M., \& Salvador, R. B. 2009. How does ethical leadership flow? Test of the trickle-down model. Organizational Behavior and Human Decision Processes, 108: 1-13.

McAllister, D. J. 1995. Affect-and cognition-based trust as foundations for interpersonal cooperation in organizations. Academy of Management Journal, 38: 24-59.

Ng, T.W. H., Eby, L. T., Sorensen, K. L., \& Feldman, D. C. 2005. Predictors of objective and subjective career success: A meta-analysis. Personnel Psychology, 58: 367-408.

Petry, E. S., Mujica, A. E., \& Vickery, D. M. 1998. Sources and consequences of workplace pressure: Increasing the risk of unethical and illegal business practices. Business and Society Review, 99: 25-30.

Podsakoff, P. M., MacKenzie, S. B., Moorman, R. H., \& Fetter, R. 1990. Transformational leader behaviors and their effects on followers' trust in leader, satisfaction, and organizational citizenship behaviors. The Leadership Quarterly, 1: 107-42.

Podsakoff, P. M., MacKenzie, S. B., Paine, J. B., \& Bachrach, D. G. 2000. Organizational citizenship behaviors: A critical review of the theoretical and empirical literature and suggestions for future research. Journal of Management, 26: 513-63.

Resick, C. J., Hanges, P. J., Dickson, M. W., \& Mitchelson, J. K. 2006. A cross-cultural examination of the endorsement of ethical leadership. Journal of Business Ethics, 63: $345-59$

Robertson, D. C., \& Rymon, T. 2001. Purchasing agents' ethical behavior: A randomized response technique study. Business Ethics Quarterly, 11: 455-79.

Rouiller, J. Z., \& Goldstein, I. 1993. The relationship between organizational transfer climate and positive transfer of training. Human Resource Development Quarterly, 4: 377-90. 
Rubin, R. S., Dierdorff, E. C., Bommer, W. H., \& Baldwin, T. T. 2009. Do leaders reap what they sow? Leader and employee outcomes of leader cynicism about organizational change. The Leadership Quarterly, 20: 680-88.

Rubin, R. S., Munz, D. C., \& Bommer, W. H. 2005. Leading from within: The effect of emotion recognition and personality on transformational leader behavior. Academy of Management Journal, 48: 845-58.

Shore, L. M., Cleveland, J. N., \& Goldberg, C. B. 2003. Work attitudes and decisions as a function of manager age and employee age. Journal of Applied Psychology, 88: 529-37.

Spence, M. 1973. Job market signaling. Quarterly Journal of Economics, 87: 355-74.

Tenbrunsel, A. E. 1998. Misrepresentation and expectations of misrepresentation in an ethical dilemma: The role of incentives and temptation. Academy of Management Journal, 41: 330-39.

Tepper, B. J. 2007. Abusive supervision in work organizations: Review, synthesis, and research agenda. Journal of Management, 33: 261-89.

Treviño, L. K. 1986. Ethical decision making in organizations: A person-situation interactionist model. Academy of Management Review, 11: 601-17.

1990. A cultural perspective on changing and developing organizational ethics. Research in Organizational Change and Development, 4: 195-230.

Treviño, L. K., Brown, M. E., \& Hartman, L. P. 2003. A qualitative investigation of perceived executive ethical leadership: Perceptions from inside and outside the executive suite. Human Relations, 55: 5-37.

Treviño, L. K., Butterfield, K. D., McCabe, D. L. 1998. The ethical context in organizations: Influences on employee attitudes and behaviors. Business Ethics Quarterly, 8: 447-76.

Treviño, L. K., Weaver, G. R., \& Brown, M. E. 2008. It's lovely at the top: Hierarchical levels, identities, and perceptions of organizational ethics. Business Ethics Quarterly, 18: 233-53.

Treviño, L. K., Weaver, G. R., Gibson, D., \& Toffler, B. 1999. Managing ethics and legal compliance: What works and what hurts. California Management Review, 41: 131-50.

Treviño, L. K., Weaver, G. R., \& Reynolds, S. J. 2006. Behavioral ethics in organizations: A review. Journal of Management, 32: 951-90.

Treviño, L. K., \& Youngblood, S. A. 1990. Bad apples in bad barrels: A causal analysis of ethical decision-making behavior. Journal of Applied Psychology, 75: 378-85.

Van Velsor, E., \& Leslie, J. B. 1995. Why executives derail: Perspectives across time and cultures. Academy of Management Executive, 9: 62-72.

Veiga, J. F., Golden, T. D., \& Dechant, K. 2004. Why managers bend company rules. Academy of Management Executive, 18: 84-91.

Weaver, G. R., Treviño, L. K., \& Cochran, P. L. 1999. Corporate ethics programs as control systems: Influences of executive commitment and environmental factors. Academy of Management Journal, 42: 41-57. 
Werhane, P. 1985. Persons, rights, and corporations. Englewood Cliffs, NJ: Prentice Hall.

Williams, L. J., \& Anderson, S. E. 1991. Job satisfaction and organizational commitment as predictors of organizational citizenship and in-role behaviors. Journal of Management, 17: 601-17. 